\title{
Imigrantes: identidades em trânsito
}

Lilian Soier do Nascimento

Resumo

Neste trabalho, discorro sobre a figura do imigrante em sua similaridade com o sujeito pós-moderno face à crise de identidade que os atravessa. Analiso brevemente a personagem Madruga, do romance $A$ república dos sonhos, de Nélida Piñon, cujo desejo de registro escrito de suas tradições e memórias presta-se como forma de resistência cultural.

Palavras-chave: Imigrante. Sujeito pós-moderno. Identidade. Memória.

As questões relativas à alteridade ocupam hoje lugar cada vez mais significativo no seio do pensamento crítico. As reconfigurações do mundo contemporâneo exigem maior compreensão de si e do outro para alcançar, ainda que minimamente, o entendimento do contexto sociopolítico da atualidade, bem como para ampliar as reflexões em torno do sujeito contemporâneo. Muitas são as discussões realizadas em torno da crise de identidade que atravessa hoje o sujeito, cujas identidades culturais de classe, sexualidade, etnia, raça e nacionalidade estão sendo deslocadas. Neste contexto de instabilidade no qual as velhas identidades se encontram em declínio e os quadros de referências que davam aos indivíduos uma ancoragem estável no mundo social já não possuem fronteiras tão definidas, a figura emblemática do estrangeiro e do imigrante torna-se objeto de reflexão privilegiados para uma observação mais de perto desses fenômenos que marcam a contemporaneidade.

José Arbex Jr., durante um simpósio sobre o estrangeiro, realizado na PUC-SE, em 1994, postulou que

Quando desabam todas as referências que antes pareciam tão seguras, o estrangeiro surge como um alvo ainda mais necessário, como uma referência que extrai sua positividade de seu valor absolutamente negativo, de tudo o que não sou e que tenho de destruir para ser eu mesmo, já que não sei mais muito bem quem sou. (ARBEX JR., 1998, p. 10).

A gradual dissolução do poder hegemônico dos estados nacionais para dar lugar a uma nova ordem mundial, cujas bases econômicas, políticas e sociais são rearticuladas, cria nos sujeitos o quadro de instabilidade ao qual José Arbex Jr. se refere. Nesse novo cenário, no mundo globalizado, as figuras do estrangeiro e do imigrante emergem, pois, com maior vigor, tornando-se mais presentes e visíveis. Mesmo no campo da literatura, tais personagens ganha em importância. O pensador Homi Bhabha, por exemplo, sugere que 
O estudo da literatura mundial poderia ser o estudo do modo pelo qual as culturas se reconhecem através de suas projeções de 'alteridade'. Talvez agora possamos sugerir que histórias transnacionais de migrantes, colonizados ou refugiados políticos - essas condições de fronteira e divisas - possam ser o terreno da literatura mundial, em lugar da transmissão de tradições nacionais, antes o tema central da literatura mundial. (BHABHA, 1998, p. 33)

Marcadamente desterritorializado, deslocado de seu lugar familiar, o imigrante encontra-se em trânsito. Ser entre culturas, torna-se símbolo da impossibilidade de apreensão totalizante do sujeito. Subjetividade sem repouso, híbrido por excelência, o imigrante faz incidir um olhar estranhado sobre os nossos conceitos de nação e de nacionalidade. É portador de uma dupla relação de aquisição e recusa identitária, na sua busca de inserção no mundo. Por isso mesmo, torna-se insígnia do sujeito contemporâneo, paradoxalmente nativo e estrangeiro, cosmopolita e de lugar nenhum. Félix Guattari, ao discorrer sobre a desterritorialização de tal sujeito, registra que a noção de terra natal, de um lugar referencial e tranqüilizador torna-se cada vez mais insuficiente para descrever a localização/identificação do sujeito no mundo (GUATTARI, 1992, p. 169). O que se tem, em contrapartida, é a prevalência de intercâmbios espaciais e culturais que se intensificam pelo advento do desenvolvimento tecnológico, que traz, virtualmente, a diversidade de paisagens, costumes, culturas e estilos, compactando espaços, aproximando diferenças. Assim, o ideário de terra natal volatiliza-se e o sujeito contemporâneo torna-se cidadão do mundo, com sua subjetividade desprovida de referenciais seguros e sujeita a constantes transformações. Paradoxalmente, o mesmo sujeito cosmopolita torna-se estrangeiro se ousar ultrapassar as fronteiras do mundo, ainda que assim reconfigurado. Basta que os interesses econômicos de qualquer ordem sejam postos em jogo pelo trânsito internacional de pessoas, para vermos estrangeiros, muitas vezes considerados detestáveis, surgirem diante de nossos olhos, desafiando as contradições do mundo pós-moderno, cujo pilar sustentador continua sendo o poderio e a dominação econômicos. A compressão do espaço-tempo, pela globalização, cria um cenário em que o fenômeno migratório mais contemporâneo se rearticula. Atualmente, a circulação de imigrantes, tanto de origem européia quanto de países do terceiro mundo, não se dá mais de forma maciça, como ocorreu no final do século XIX e início do XX, mas através de fluxos contínuos (geralmente refreados por regulamentação de leis de restrição) e diversificados sob as mais diferentes modalidades e roupagens.

[...] a interdependência global agora atua em ambos os sentidos. O movimento para fora (de mercadorias, de imagens, de estilos ocidentais e de identidades consumistas) tem uma correspondência num enorme movimento de pessoas das periferias para o centro, num dos períodos mais longos e sustentados de migração "não-planejada" da história recente. [...] as pessoas mais pobres do globo, em grande número, acabam por acreditar na "mensagem" do consumismo global e se mudam para os locais de onde vêm os "bens" e onde as chances de sobrevivência são maiores. (HALL, 1999, p. 81)

A pobreza, a fome, a falta de oportunidades de trabalho e o baixo padrão de qualidade de vida que marcaram os grandes movimentos migratórios do início do século XX continuam sendo fatores importantes de mobilização humana pelo globo. Tentar, então, entender essas figuras tão características da contemporaneidade leva o nosso olhar a recuperar figuras semelhantes no passado, seja para com elas traçar uma linha histórica, seja para ressignificá-las pelo olhar teórico contemporâneo. Identificar, na abordagem ficcional que se tem do imigrante da virada do século XX, os atributos de estrangeiridade pertinentes ao sujeito contemporâneo abre, pois, perspectivas para uma releitura da imigração e de seus desdobramentos, bem como 
para perceber a diversidade de abordagens que essa temática propicia no âmbito crítico e literário. A possibilidade de se realizarem deslocamentos, no tempo e no espaço, propicia um desprendimento de uma cronologia rigidamente historicista para problematizar o fenômeno imigratório em sua complexidade e perceber a ficção como possibilidade de reconstituir, em novas bases, mesmo recriar, a história da imigração. Por outro lado, subjazem à trajetória do imigrante da virada do século questões como desenraizamento, fragmentação e negociação de identidades, experiências que, de resto, também atravessam o sujeito na contemporaneidade.

Madruga, personagem do romance $A$ república dos sonhos, de Nélida Piñon, exemplifica essa condição. Imigrante galego, estabelecido no Brasil, conseguiu negociar a partir de sua condição de estrangeiro e transitar entre patrícios e nativos da terra, para deles extorquir as vantagens pelas quais pôde acumular bens e capital e inserir-se na sociedade brasileira.

A riqueza adquirida, após anos de fastidioso trabalho, não pôde, por si mesma, conferir-lhe $o$ acesso aos circuitos fechados da elite brasileira. Foi necessário atrelar filhos/fortuna e influência para adquirir status, projeção social. Através do casamento arranjado de seus filhos, as portas mais cerradas, enfim, foram-lhe abertas. "Comprei Luiz Filho e o regalei à filha Antônia. Ele teve que ceder o valioso sobrenome diante do preço pago" (p. 162). O genro de Madruga provinha de uma família quatrocentona ( $p$. 162), cuja riqueza residia nas tradições de nobreza, estando, contudo, em franca decadência financeira. Eram os recursos do imigrante galego que garantiam a manutenção da posição social ao fidalgo brasileiro, mais que o nome e a tradição conferidos a Antônia pelo matrimônio. Também o casamento de Tobias com Amália foi resultado das manobras de Madruga, que "praticamente exigiu o casamento [...] por ser Amália uma herdeira rica" (p. 48), filha de um bem sucedido imigrante italiano que, segundo Madruga, havia "desembarcado na América com a miséria na alma" ( $p$. 48). Quanto à esfera política, a manobra para inserir-se nesse circuito foi semelhante. Bento casou-se com a "filha de um ministro do Supremo Tribunal Federal, íntimo amigo de Juscelino" (p. 214). A construção de Brasília resultou em maior enriquecimento para a família que contava com a ajuda do novo sócio, o senador Silveira, junto de quem habilitava-se "às concorrências previamente ganhas" (p. 214).

Enriquecer. Fazer a América. Esse era o sonho que impulsionou Madruga a atravessar o Atlântico. A construção da América que ele intenta realizar está relacionada à casa simbólica a ser engendrada através da constituição de uma família brasileira. Ao processo de construção dessa casa dá-se a apropriação de um lugar também simbólico. Não basta construir. Há que inseri-la em um lugar socialmente proeminente no cenário nacional.

- Estamos no Brasil há quase vinte anos, e ninguém ainda se deu conta de que existimos. Dependerá de nós ganharmos uma dimensão concreta [...] caso contrário, seremos uns eternos coitados. Nada pior que um imigrante fracassado (p. 155).

Visto que é também pelo discurso que se determinam os lugares sociais e se estabelecem os parâmetros de reconhecimento mútuos em uma dada comunidade, há que se apoderar dos valores atribuídos aos pertencentes ao grupo social almejado para tornar-se reconhecidamente parte integrante dele. Colocar em ação os subterfúgios pelos quais possa acessar o topos que almeja é parte do trabalho que a apropriação de um espaço dentro da domesticidade brasileira requer. O desejo de realizar essa construção e apropriação fez com que a personagem lançasse mão também do patrimônio familiar acumulado para infiltrar-se, sorrateiramente, em territórios restritos da esfera política e social do país e deles tomar parte. 
Figura emblemática, representante de tantos imigrantes, não só espanhóis, que atravessaram o território nacional e ajudaram a compor a população brasileira, Madruga é personagem central da saga imigratória construída no romance e exemplo do ethos oscilante de quem deixa a terra natal para aventurar-se em outro território, e cuja negociação identitária nunca pode ser dada como completa.

A personagem em toda a sua trajetória tenta, pelo veio da memória, resguardarse da aniquilação de suas tradições, de ver desintegrarem-se os resquícios de sua identidade galega, que já se encontra traduzida em solo brasileiro. Madruga, pelo registro escrito, intentará perpetuar a existência de seus ascendentes e descendentes legando à neta Breta a missão de produzir um outro e mesmo livro, a fim de tentar resguardar as histórias e tradições de sua ancestralidade. É em torno dos interstícios da memória, de seus vazios e lacunas que a história desse imigrante se encena como forma de resistência cultural, permanecendo, contudo, em aberto, à semelhança de sua fragmentada identidade.

Abstract

In this work, I analise the immigrant figure in its similarity to the post-modern individual, highlighting the identity crisis which both of them face. Moreover, I briefly analise Madruga, the main character of Nelida Piñon's novel A república dos sonhos, who by his desire of having his tradition and memories registered in written words, represents a form of cultural resistance.

Key words: Immigrant. Post-modern individual. Identity. Memory.

Referências

ANDERSON, B. Comunidades imaginadas: reflexiones sobre el origen y la difusión del nacionalismo. México: Fondo de Cultura Económica, 1993.

ARBEX JÚNIOR, José. A construção do estrangeiro pela mídia. In: KOLTAI, Caterina (Org.). O estrangeiro. São Paulo: Escuta /

FAPESP, 1998.

BELLEI, Sérgio Prado. Nacionalidade e literatura: os caminhos da alteridade. Florianópolis: UFSC, 1992.

BHABHA, Homi K. O local da cultura. Belo Horizonte: Ed. UFMG, 1998.

BOSI, Ecléa. Memória e sociedade: lembrança de velhos. São Paulo: Companhia das Letras, 1994.

BOURDIEU, Pierre. Um analista do inconsciente. In: SAYAD, Abdelmalek. A imigração ou os paradoxos da alteridade. Tradução Cristina Murachco. São Paulo: USP, 1998. (Prefácio)

CURY, Maria Zilda F. Navio de imigrantes, identidades negociadas. São Paulo: Fundação Memorial da América Latina, 2002.

FAUSTO, Boris (Org.). Fazer a América. São Paulo: EDUSP, 2000. 
GUATTARI, Félix. Caosmose: um novo paradigma estético. Rio de Janeiro: Ed. 34, 1992.

HALL, Stuart. A identidade cultural na pós-modernidade. Rio de Janeiro: DP\&A, 1999.

KOLTAI, Caterina (Org.). O estrangeiro. São Paulo: Escuta; FAPESP, 1998.

NASCIMENTO, Lilian Soier. A identidade do imigrante e a construção da memória: A república dos sonhos, de Nélida Piñon. Revista Vertentes, São João Del Rei: FUNREI, n.17, p. 49-54, jan./jun. 2001.

OLIVEIRA, Lúcia Lippi. O Brasil dos imigrantes. Rio de Janeiro: Jorge Zahar, 2001.

PIÑON, Nélida. A república dos sonhos. Rio de Janeiro: Francisco Alves, 1984.

SAYAD, Abdelmalek. A imigração: ou os paradoxos da alteridade. Tradução de Cristina Murachco. São Paulo: EDUSP, 1998.

SCHWARCZ, Lilia Moritz.(org.) História da vida privada no Brasil: contrastes da intimidade. São Paulo: Companhia das Letras, 1998.

SOJA, Edward W. Geografias pós-modernas: a reafirmação do espaço na teoria social crítica. Rio de Janeiro: Jorge Zahar, 1993. 